\title{
HETEROGENEIDADE DA FORMA DE UM SETOR URBANO NO DISTRITO DO TREMEMBÉ
}

\section{MACEDO, ADILSON COSTA}

PhD, Universidade São Judas Tadeu, e-mail: ac.macedo@terra.com.br

\section{DAMASCENO, RODRIGO LUZ}

Arquiteto, Universidade São Judas Tadeu, e-mail: rodrigo_damasceno_5@hotmail.coml

\begin{abstract}
RESUMO
Este artigo se situa no campo da Morfologia Urbana, em que a história é o pano de fundo de fatos que promoveram a transformação do desenho da cidade. Trata, especificamente, do tecido urbano de um setor do bairro do Tremembé, cidade de São Paulo, cujas diferenças no projeto de urbanização refletem as desigualdades socioeconômicas dos seus moradores, contexto que sugeriu adotar-se como objeto de pesquisa o tipo de constructo destinado a moradia. Ali, os edifícios têm altura de até quatro pavimentos e são implantados em conjunto com residências térreas ou assobradadas, isoladas ou em fileira. Além da identificação destes elementos urbanos, o artigo discute os padrões de configuração do espaço exterior, o traçado, o relevo do terreno, a vegetação e a infra-estrutura.

PALAVRAS-CHAVE: bairro periférico; forma urbana; projeto urbano.
\end{abstract}

\section{RESUMEN}

Este artículo se sitúa en el campo de la Morfología Urbana, en lo cual la historia es el telón de fondo de hechos que producirán la transformación del diseño de la ciudad. Se trata del tejido urbano de un sector del barrio del Tremembé, ciudad de São Paulo, cuyas diferencias en el proyecto de urbanización reflejan las desigualdades socioeconómicas de sus habitantes, situación que sugirió tomar como objeto de pesquisa el tipo de constructo destinado a la vivienda. Alli los edificios tienen altura de hasta cuatro pavimentos y se implantan en conjunto con residencias térreas o silbadas, aisladas o en fila. Mas que la identificación de estos elementos urbanos. El articulo discute los patrones de configuración del espacio exterior, el trazado, el relieve del terreno, la vegetación y la infraestructura.

PALABRAS CLAVE: barrio periférico; forma urbana; proyecto urbano.

\section{ABSTRACT}

This article is in the field of Urban Morphology where history is the background of events that led to the transformation of the city's design. It deals with the urban fabric of a sector of the district of Tremembé, in the city of São Paulo, whose differences in the urbanization project reflect the socioeconomic inequalities of its residents. This context suggested to take the type of construct destined to dwell as object of research. There, the buildings have height of up to four floors and are implanted together with single or combined single or row houses. Together with the identification of these urban elements, the patterns of configuration of the outer space, the layout, the relief of the terrain, the vegetation and the infrastructure are discussed.

KEYWORDS: peripheral district; urban form; urban design.

\section{PRELIMINARES}

Demonstra-se a diferença entre três tipos de ocupação do espaço físico que ocorrem em um setor do distrito do Tremembé, localizado na zona norte da cidade de São Paulo. O distrito corresponde a superfície de cinco mil seiscentos e trinta hectares com população aproximada de cento e noventa e sete mil habitantes. O setor destacado para estudo tem a superfície de oitenta e três hectares e população equivalente a nove mil e quatrocentas pessoas. Para a análise da forma urbana deste pequeno setor, face à dimensão do distrito, é considerada a apropriação do território através das vias, quadras, lotes, tipos de edificação e de espaços livres, aproveitando as possibilidades oferecidas por um sítio de desnível acentuado. O pano de fundo da investigação sobre os tipos de edificar acontece pela história do desenvolvimento da área, que espelha desigualdades sociais através do arranjo de espaços e da qualidade das construções.

Nesse estudo o setor foi subdividido em três subsetores cuja proximidade e por suas características físicas espelha três diferentes níveis de renda, fato observado no Tremembé, mas que é constante nos bairros periféricos de São Paulo. A pesquisa, baseada em trabalho de campo, chega a um resultado contrário à 
crença corroborada por planejadores urbanos que generalizam o dito de haver um cinturão de pobreza ao redor da área central da cidade. Tal afirmação precisa ser expressa com maior cuidado, pois existem manchas urbanizadas para padrões de renda alto e médio presentes nas áreas periféricas de São Paulo, as quais são ocupadas por gente que melhorou o poder aquisitivo e que decidiu não migrar para local de maior prestígio em troca de permanecer perto do trabalho, por laços de família e pelos amigos ou, ainda, por um empreendimento que cresceu, por estar localizado em ponto estratégico.

Embasando o desenvolvimento deste artigo foram empregados conceitos relacionados ao estudo da forma urbana, suporte de onde nasceram os procedimentos para a pesquisa e obtenção do material ora condensado na forma de artigo.

\section{REFERÊNCIA A CONCEITOS}

O trabalho se desenvolve por procedimentos analíticos aplicados a uma área de grande dimensão. De modo interativo, busca-se inicialmente entender a região, a acessibilidade e o distrito como um segmento do espaço maior para, finalmente, se deter nos oitenta e três hectares (83 ha) correspondentes ao setor selecionado como área-estudo (ROSSI, 2001). O procedimento adotado para conhecer o setor foi o pesquisador percorrer o local a pé, com os recursos de fotografar, anotar por textos breves e fazer croquis das informações. Este procedimento foi integrado ao trabalho de escritório, onde os dados foram classificados e processados, o que facilitou a determinação dos tipos de lote, edificações e logradouros. Com apoio no estudo tipológico se estabeleceu a relação do espaço construído com a sua implantação, primeiro no distrito do Tremembé para caracterizar e diferenciar os setores, e depois com mais detalhes no setor escolhido como área-estudo.

O tecido urbano é formado por um conjunto de configurações, pois o terreno natural se transforma por elementos como o traçado viário formador da malha de quadras, seu parcelamento em lotes, os diversos tipos de uso e ocupação do solo. A camada de tempo sobreposta a esses elementos é o dado que indica as modificações realizadas na cidade ao longo dos anos.

Refiro-me à construção da cidade no tempo. Considero que esse ponto de vista, independentemente de meus conhecimentos específicos, pode constituir o tipo de análise mais abrangente da cidade; ela remete ao dado último e definitivo da vida da coletividade: a criação do ambiente em que esta vive (ROSSI,1966, p.1).

A citação acima discursa sobre a leitura do tecido urbano através de seu dado último, ou seja, a sua construção mais recente, entendida como aquela em que a sociedade participa das alterações em curso e atua sobre o tecido histórico e consolidado através do tempo. Nesta narrativa parte-se do dado último para a compreensão do setor urbano escolhido para estudo, sem deixar de lado os constituintes históricos do contexto maior onde ele se situa. Considera-se que desde os anos cinqüenta do século $\mathrm{XX}$, o processo de ocupação do município se tornou complexo. O deslocamento da classe dominante das áreas centrais no sentido sudoeste, o deslocamento da indústria automobilística para municípios vizinhos, o crescimento periférico acentuado, um ambiente de crise e diminuição do poder de compra, bem como a questão da localização e o preço da terra, são fatores importantes que ajudam ilustrar a complexidade do tecido urbano da cidade de São Paulo.

O estudo dos tipos de ruas, quadras, edificações, gabaritos, vegetação e uso do solo, contribuem para o entendimento dos espaços que configuram os lugares das pessoas e formam a base para eventuais proposições.

O conceito de tecido urbano exprime a realidade da cidade construída, matéria com existência real e temporal, que inclui indissociavelmente o espaço e o edificado, o público e o privado, isto é, as ruas, as parcelas, os edifícios, as infra-estruturas, etc., isto é, toda a cidade física (COELHO, 2013, p. 14)

O tecido urbano se refere à cidade construída, tridimensional. Sua representação como projeto subentende a existência de desenhos, o plano da cidade, o traçado como se diz em Portugal. O arquiteto-professor Coelho oferece a seguinte definição: 
O traçado conceito abstrato e bidimensional é obtido por um processo redutor ao retirar ao tecido urbano uma das suas três dimensões. Remete para a representação do espaço público e da estrutura parcelar, indiferenciado os vários elementos que os materializam. Ao primeiro componente - o espaço público -estruturador das parcelas individuais, podemos chamar de Traçado Urbano; ao segundo, menos perceptível na globalidade, mas pelo contrário mais sujeito ao processo evolutivo, podemos simplesmente chamar de Parcelário (COELHO, 2013, p. 31).

O autor chama atenção para dois elementos importantes do projeto urbano: o traçado, ou o desenho do viário estruturador das quadras; e as quadras, espaços menores divididos em partes ainda menores que são os lotes, o parcelário como chamam os colegas portugueses. Como afirma o professor, estes elementos estão sujeitos a alterações no tempo.

A relação do traçado com o relevo do território, fundamental no projeto urbano, é descrita pelo arquitetoprofessor Sergio Padrão Fernandes, citado no capítulo 2 do livro de Coelho, como:

(...) o relevo imprime no traçado urbano os limites naturais do território evidenciando a transição entre zonas com características morfológicas distintas que se reflectem na variação morfológica do traçado urbano de acordo com a alteração dos pendentes das encostas (COELHO, 2013, p. 38).

Para a análise da forma urbana, objeto da investigação cujo resultado está comentado neste artigo, tem-se em consideração três fases de desenvolvimento, como proposto pelo arquiteto-urbanista Manuel de SoláMorales:

I. Crescimento suburbano: coincide com o início das ocupações na região, quando no século XIX a abertura de vias ocorreu antes do parcelamento da área.

II. Urbanização geral: quando os caminhos gerados anteriormente se consolidaram e deram lugar a avenidas estruturadoras do distrito, como é o caso da Avenida Antonelo da Messina e da Rua Maria Amália Lopes de Azevedo. Mencionadas, pois tem papel importante no setor ora indicado para estudo.

III. Urbanização marginal: caso em que o território é parcelado e posteriormente são comercializadas e construídas edificações.

A partir da década de 1950, com a aceleração do crescimento da mancha urbanizada em direção à periferia, algumas áreas ao norte do distrito passaram a ser identificadas como de urbanização marginal, onde o território foi parcelado, vindo aos poucos às edificações e somente mais tarde a urbanização através da implantação de infra-estruturas como um todo, ou quase. A Rua Maria Amália Lopes de Azevedo atualmente é a principal via que atravessa o distrito do Tremembé com extensão de 4,3 km; esta via funciona como o eixo de circulação suporte de um corredor de uso misto que se estende no sentido Leste-Oeste do distrito (MORALES, 1997, p.27).

Como pequena porção de um universo maior de urbanização o setor objeto de pesquisa foi estudado desde seu suporte natural visível, ou seja, não considerando os elementos do subsolo. Entendendo-se que a arquitetura da cidade brota e modifica a superfície do solo e acima dele, tendo respeito às implicações da infra-estrutura e demais condições devidas ao subsolo. Fica-se no universo do urban design, disciplina que, como define Jonathan Barnett (2003), trata do projeto da cidade sem projetar cada edifício, ou seja, sem avançar no campo do edifício isolado específico da Arquitetura.

Por sua vez, o tecido urbano, entendido nas suas pequenas partes, resulta do modo das pessoas se apropriarem dos espaços e indica padrões de uso que acabam por gerar tipos de construção ou abrigo de atividades das pessoas. Estes são pontos interessantes para investigar, que aparecem no Tremembé (ALEXANDER, 2013).

No que se refere à natureza do espaço, um sistema de vias se identifica pela largura e pelo tipo de piso das faixas de rolamento, se há tráfego de ônibus ou outro veículo pesado, se existe ciclovia, pela qualidade das calçadas, paisagismo, mobiliário urbano e sinalização. Estes elementos que são atributos de uma via de boa qualidade a determinam do ponto de vista funcional. As fachadas das edificações, construídas no alinhamento dos lotes ou acompanhando recuo obrigatório, havendo gradil ou não no alinhamento da calçada, determinam o limite visual que define o recinto da rua, enclosure da língua inglesa (EWING, 2013). Portanto, a 
compreensão do espaço da via segundo o ponto de vista da forma urbana tem a ver com uma questão de ordem funcional em conjunto com outra que se refere a percepção visual.

De acordo com sua extensão e funcionalidade, as vias são consideradas em apenas três tipos para efeito de análise da forma urbana: as que atravessam, as que distribuem e as locais. Tal estudo tem foco no perímetro do setor urbano que esteja sendo estudado, ou seja, dependendo da dimensão do setor em estudo e sua posição relativa, uma via de distribuição na escala da cidade poderá ser considerada como uma via que atravessa no âmbito do setor.

No desenvolvimento da análise foram utilizados os conceitos de setores definidos pelo sistema de vias, segundo três categorias:

- Vias que atravessam - aquelas que cortam ou tangenciam a área de estudo;

- Vias que distribuem - que fazem a ligação entre as vias que atravessam, distribuindo o tráfego das que atravessam para as vias locais.

- Vias locais - as que acessam os locais mais protegidos do trânsito de passagem, incluem o tipo loop e cul-desac.

Adicionando-se as faixas lindeiras de lotes elas constituem corredores, que remetem a classificação da via de origem: corredor que atravessa e corredor que distribui. As vias locais não chegam a ser corredores no sentido dos fluxos de passagem de veículos e uso do solo; por sua vez, os corredores do tecido urbano tradicional se interceptam formando células onde os fundos dos lotes definem uma superfície poligonal chamada de subárea (MACEDO, 2002).

O traçado viário resulta da subdivisão do espaço em quadras e do contorno de espaços livres e verdes. No caso dos espaços livres e/ou verdes o contorno por vias para veículos e pedestres tem o papel importante de garantir a acessibilidade de todas as pessoas a estes locais.

\section{DISTRITO DO TREMEMBÉ E O SETOR DE ANÁLISE}

A área em estudo foi o distrito do Tremembé (5.630 hectares), que está localizado na Zona Norte do município de São Paulo e dista 13 quilômetros da região central da cidade. Sua população é de 197.258 habitantes (dados atuais, Prefeitura do Município de São Paulo); devido à presença no distrito de uma parte do Parque Estadual da Serra da Cantareira, a densidade demográfica é baixa, próxima a 35 habitantes por hectare. $\mathrm{Na}$ Figura 1 destaca-se o município de São Paulo em relação à sua região metropolitana. Nela, o círculo (preenchido) indica a localização da área de estudo, cujo perímetro corresponde a 1,47\% (83 hectares) da área do distrito do Tremembé. A região central de São Paulo está indicada por um anel. A área selecionada para estudo (Figura 2) está indicada no polígono preenchido em preto, no desenho que mostra o distrito do Tremembé. Nele é possível verificar a mancha ocupada pelo Parque Estadual da Serra da Cantareira, porção noroeste do mapa.

O cálculo populacional por estimativa deve-se ao levantamento do número de residências existentes em cada um dos três subsetores. Foi utilizado o número 3,3 habitantes por residência - IBGE, 2010 - como parâmetro de referência. A somatória do número de moradores por domicílio leva a população do setor a 9.417 pessoas, das quais 2.778 habitam o subsetor 1 (resultando em 76,50 hab/ha); 5.377 moram no subsetor 2 (com 50,80 hab/ha) e 1.277 estão no subsetor 3 ( 9,67 hab/ha). 


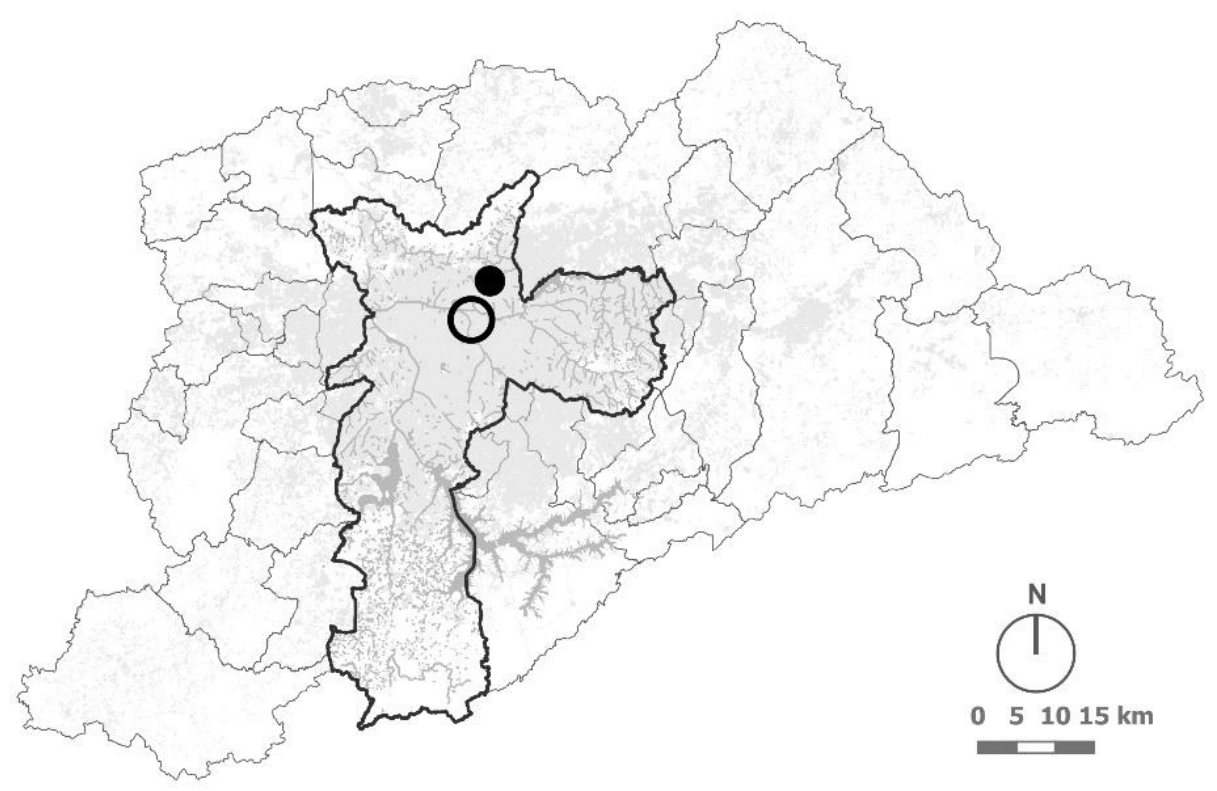

Fonte: Desenho elaborado pelos autores.

Figura 2: Distrito do Tremembé, posição relativa do setor de estudo

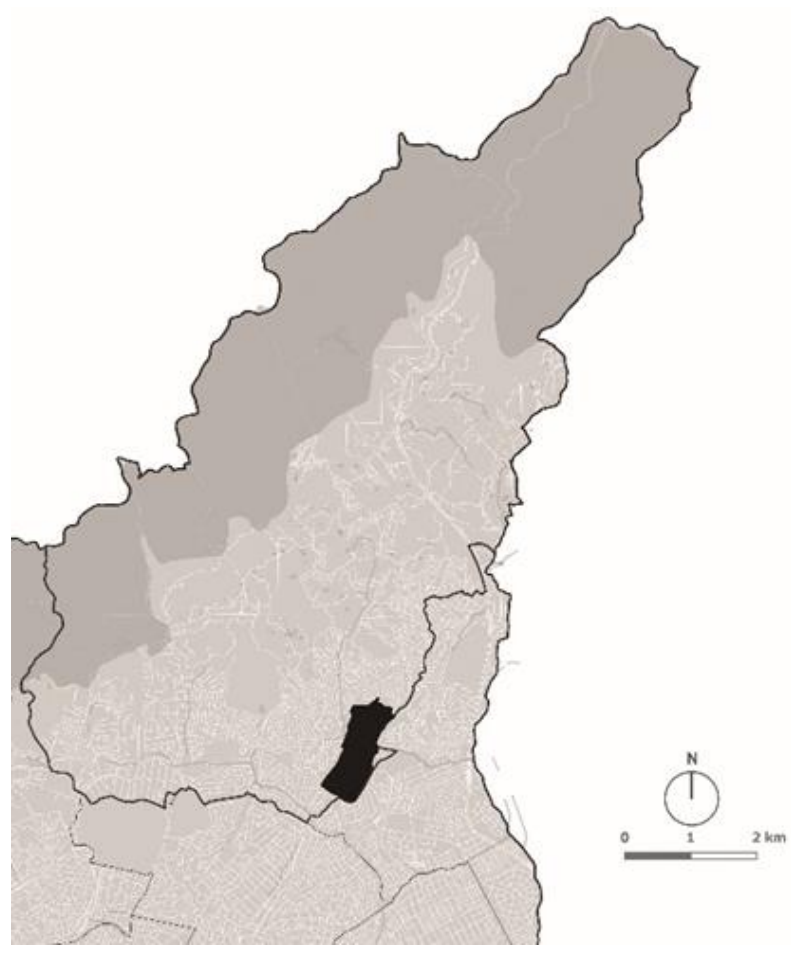

Fonte: Desenho elaborado pelos autores.

O projeto de urbanização do setor conta com trinta e três quadras, assim classificadas: treze quadras pequenas, com área até 1 ha; dezessete quadras médias entre 1 ha e 4 ha; 3 quadras grandes, maiores que 4ha. A quadra maior, com 16,5 ha, é ocupada pelo Conjunto Habitacional Jardim Apuanã. Sem contar a ocupação irregular dos córregos, nas quadras de tamanho pequeno e médio observa-se parcelamento em lotes para residências, variando desde muito pequenas, com $60,00 \mathrm{~m}^{2}$ até maiores que $500,00 \mathrm{~m}^{2}$ (estes no subsetor 3). 
O estudo do tecido urbano do setor é apresentado por temas que compõem a configuração da cidade, considerados desde o espaço físico natural, e distribuídos em:

- Superfície do terreno natural ou modificado, seus desníveis, os diferentes cursos de água ou canais, reservatórios a vegetação nativa ou não.

- Traçado da cidade, as vias que atravessam, as que distribuem e as locais.

- Espaços livres de edificações, parques e praças pavimentadas ou não incluindo as áreas esportivas.

- Espaços construídos cobertos para abrigar as atividades humanas, edificações térreas e verticalizadas.

- Maneiras de apropriação do espaço dos corredores e das subáreas.

O setor em análise é apresentado na Figura 3: em 3A (foto aérea) pode-se notar três tipos distintos de ocupação; em 3B, o diagrama mostra a localização de cada subsetor, onde o subsetor 1 (11ha) corresponde a superfície de cor preta, o subsetor 2 (32ha) está representado pelo pontilhado escuro, e o subsetor 3 (40ha) pelo pontilhado claro. Os níveis do terreno variam de pontos mais altos nos subsetores 1 e 3 para os pontos baixos junto aos córregos existentes. O setor fica em uma situação de meia encosta com inclinação que favoreceu a construção de casas em fileira.

O sistema de circulação principal se faz por duas vias: a Rua Maria Amália Lopes de Azevedo (A1) atravessa o setor no sentido oeste-leste e faz uma inflexão de noventa graus em direção sul; a Avenida Antonelo da Messina (A2) parte da Rua Maria Amália em direção norte, tangenciando os subsetores 1 e 2. Estas são consideradas as ruas mais importantes do setor em estudo, chamadas vias que atravessam. Desenhadas com espessura média estão aquelas consideradas como vias de distribuição, pois distribuem o tráfego para as vias locais e não são realçadas no diagrama. Os córregos existentes estão assinalados por duas linhas finas.

Nas respectivas faixas lindeiras dos lotes localizados nas vias que atravessam A1 e A2, as edificações são ocupadas por comércio, serviços e atividades institucionais de interesse para o setor 3 , bem como para uso das pessoas em trânsito para outros destinos.

Apresentam-se a seguir observações sobre cada subsetor, questões de análise urbana e projeto urbano que serão vistas na prática, na escala do subsetor.
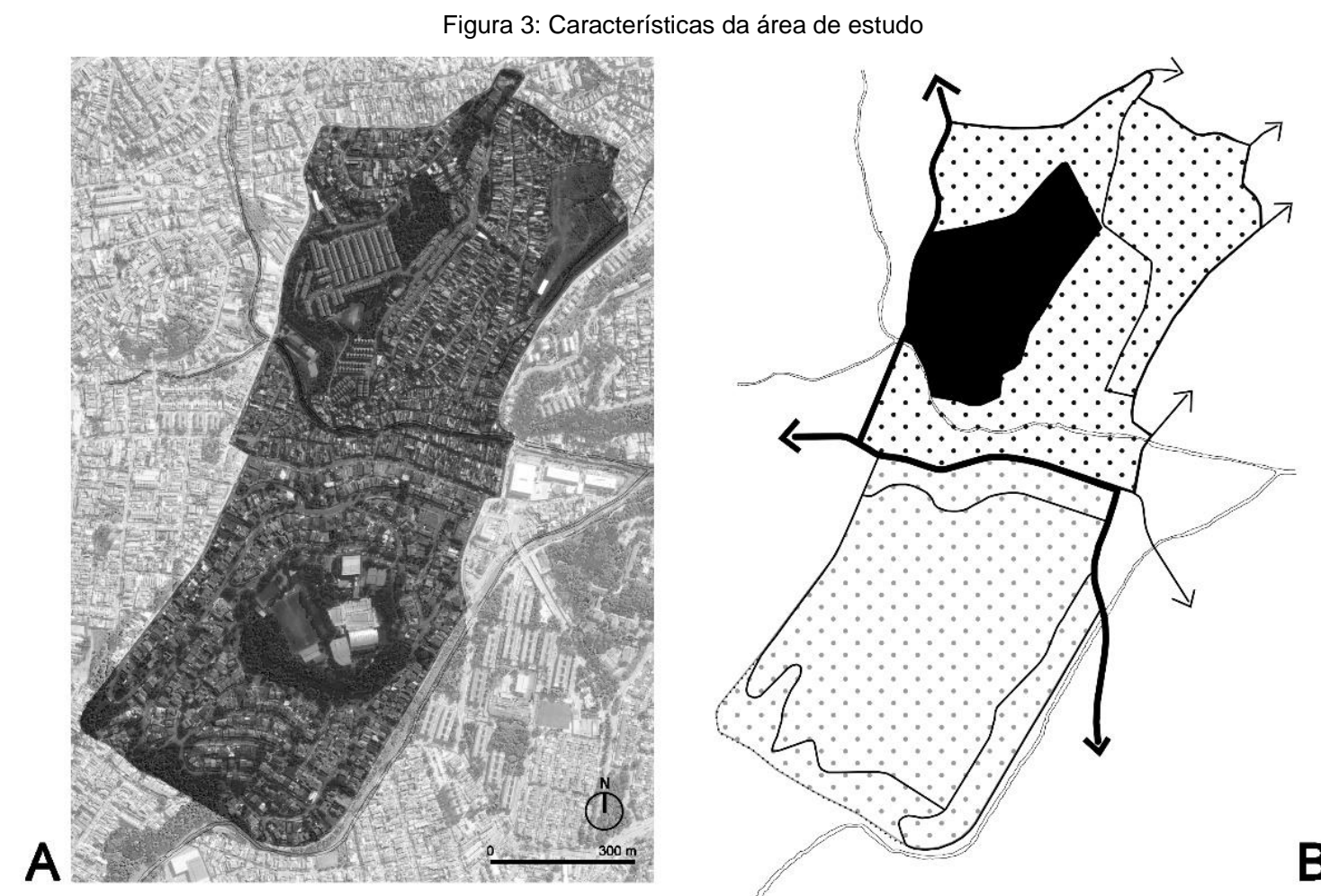

Fonte: Elaborado pelos autores, Google Earth e Mapa Digital da Cidade. 


\section{Vias públicas do setor em estudo e o parcelamento do solo}

No Tremembé as vias de cada subsetor têm peculiaridades, seja pelo seu assentamento no terreno em declive, seja pela largura do leito carroçável, ou pela presença ou falta dos elementos urbanos. O que existe não preenche o conjunto de elementos urbanos que deveriam compor as vias,e thes auferirem qualidade conforme os indicadores que classificam as vias por padrão de qualidade (tópico anterior). Em cada subsetor se atestam as diferenças, fruto da largueza ou dificuldades para a construção de cada um dos espaços. É evidente a diferença de qualidade do espaço público em cada subsetor e observa-se que isto reflete o tipo de tecido urbano que foi previsto pelo projeto.

Os subsetores 1 e 3 são os que tem melhor qualidade urbana. Vias, passeios largos, vegetação nas calçadas são algumas das características desses locais, apesar de que a faixa de renda dos residentes nestes subsetores seja distinta. $\mathrm{O}$ subsetor 2 caracteriza um tipo de loteamento precário, devido a estreiteza das vias, dos passeios, a falta de espaços livres e descuido com as edificações. Observa-se o descaso com o cuidar dos espaços comuns, tanto por parte do poder público quanto por parte da comunidade - situação compreensível em locais de baixa renda no Brasil, que pode estar ligada à pouca civilidade de parte significativa dos moradores.

Nos subsetores as vias deveriam definir o contorno das áreas livres e ou verdes, inclusive acompanhar faixas de proteção ambiental dos cursos d'água, com o objetivo de permissão da acessibilidade pública. No setor em estudo como um todo existe cobertura vegetal significativa, porém não distribuída de maneira homogênea. Ela se localiza em dois maciços, ao norte no subsetor 1, ao sul no subsetor 3 . O subsetor 2 , é o que apresenta menor quantidade de área vegetada, devido ao traçado da área se fazer por vias estreitas e lotes de pequenas dimensões, havendo pouca vegetação nos passeios e no interior dos lotes. A ausência de arborização acontece também nas duas vias principais. A faixa de mata ciliar ao longo dos córregos, que seria parte da faixa de proteção ambiental, está comprometida devido a ocupação por moradias precárias localizadas de forma irregular (Figura 4): em 4A, destaca-se o sistema viário principal; em 4B, o diagrama mostra a projeção dos prédios.

O subsetor 1 possui a maior densidade demográfica devido à verticalização do conjunto habitacional e a área total ser relativamente pequena. $O$ subsetor 2 , devido aos lotes pequenos para as residências e as residências geminadas. $O$ subsetor 3 , por ser ocupado por residências de classe média.

Figura 4: plano geral e diagrama figura fundo (figure ground)
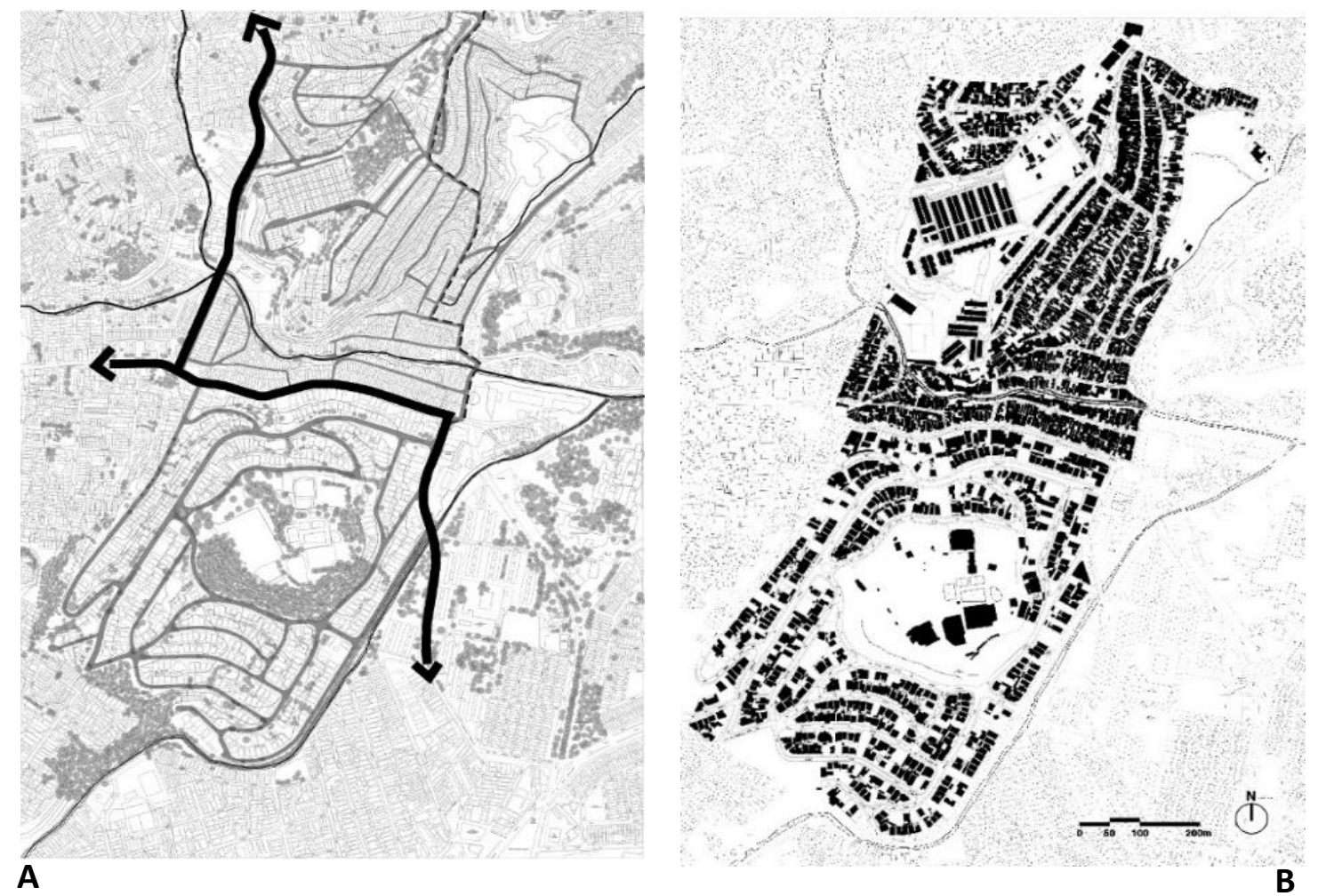

Fonte: Diagrama elaborado pelos autores. 
Macedo, A. C.; Damasceno, R. L.

\section{Subsetores}

Edifícios em altura não ocorrem de forma significativa no setor, apenas no subsetor 1 , Conjunto Habitacional Jardim Apuanã existem edificações até quatro pavimentos, o que caracteriza o perfil de horizontalidade do setor. Comparados os três subsetores, o primeiro deles possui o maior gabarito, tendo sido implantado em local de cota alta. As demais edificações são do tipo casa térrea ou assobradada, a menos onde se tirou partido da topografia e se conseguiu mais um ou dois pavimentos. Em diversas situações o espaço destinado a uma residência no lote, serviu para a construção de edificação com a finalidade de abrigar mais do que uma família.

No subsetor 1, além dos prédios existem conjuntos formados por casas. No subsetor 2, quase todo, as moradias são pequenas, construídas em fileira ou são produto da ocupação informal dos terrenos junto ao córrego. No subsetor 3, as casas estão isoladas no lote. A seguir apresentam-se os tipos de configuração das moradias conforme seu projeto responde ao programa de necessidades. Em cada um destes subsetores demonstra-se de maneira sintética o material observado pela pesquisa. A foto aérea e outras tiradas no local oferecem a idéia do contexto onde se insere cada subsetor.

\section{Subsetor 1}

Neste subsetor destaca-se o conjunto de prédios implantado na cota mais alta, a ocupação por casas projetadas em fileira (geminadas) e o espaço verde abrangendo quase metade da área do subsetor. $O$ empreendimento habitacional teve início em 1990, na gestão da Prefeita Luíza Erundina, através da Associação dos Sem-Terra, tendo sido sua construção executada em mutirão devidamente orientada por projeto de arquitetura e de infra-estrutura. A construção por mutirão foi adotada também para as partes ocupadas por residências (Figura 5).

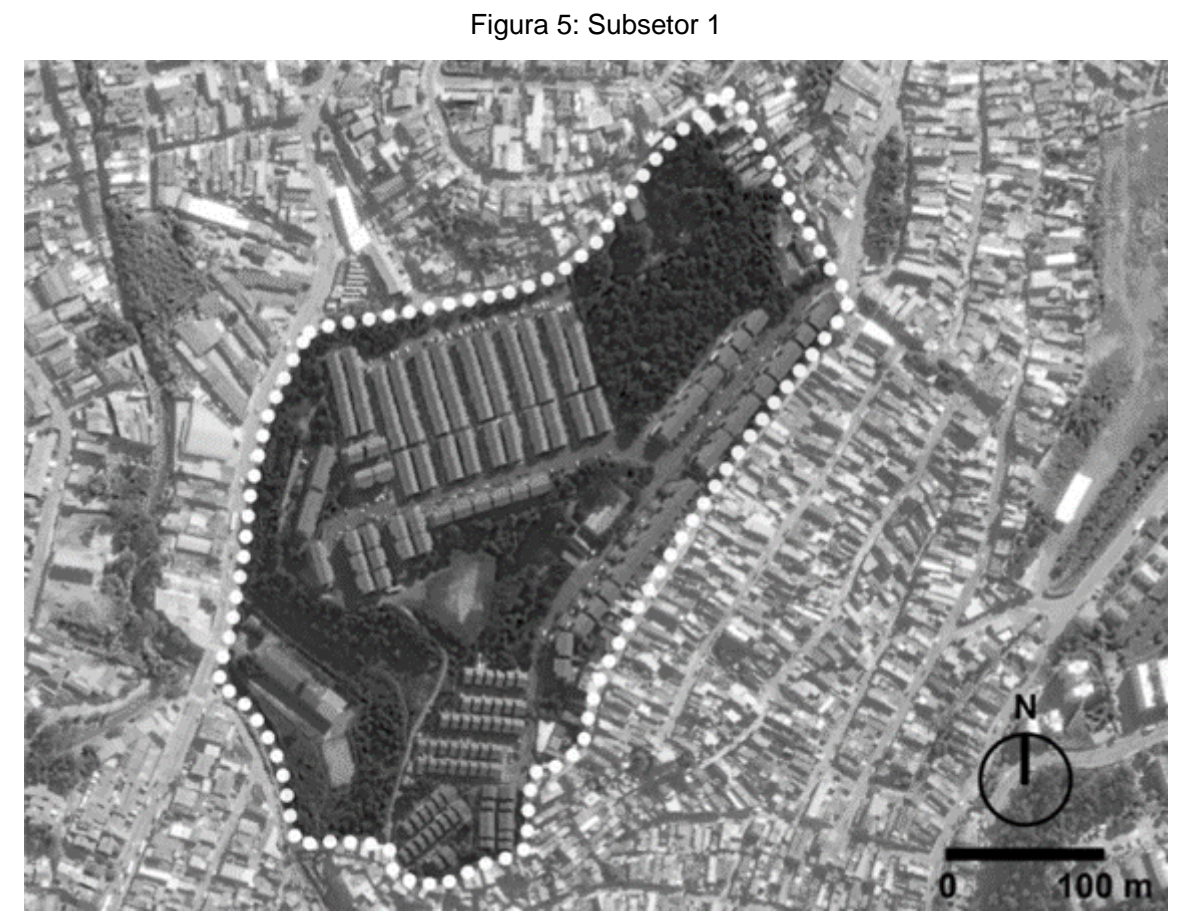

Fonte: Google Earth, retrabalhado pelos autores.

Há duas situações distintas de leitos carroçáveis nesse subsetor e que ocorrem de modo paralelo. A primeira é a Avenida Antonelo da Messina presente em fundo de vale (à esquerda na figura 5) e a segunda é a Rua Um, na cumeeira (à direita na Figura 5), e que permite acesso ao interior do conjunto. A avenida tem um caráter de corredor de circulação principal, devido à conexão com as vias de menor escala no bairro, além de escoar o transporte público da região. A segunda via, ligada ao Conjunto Jardim Apuanã, possui um caráter apenas de acesso às residências dentro do empreendimento habitacional, tanto que essa via termina em culde-sac. 
Macedo, A. C.; Damasceno, R. L.

O subsetor 1 está implantado em uma área de topografia acidentada, contendo blocos de apartamentos (unidades de $40 \mathrm{~m}^{2}$ ) e casas geminadas (unidades de $35 \mathrm{~m}^{2}$ ). As casas têm uma planta convencional de moradia popular.

Os prédios têm um bom projeto, com planta flexível, e apartamento de dois quartos (Figura 6). As plantas dos apartamentos são bastante funcionais e projetadas para a construção em alvenaria armada (Figura 7).

Figura 6: Setor 1, apartamentos e casas
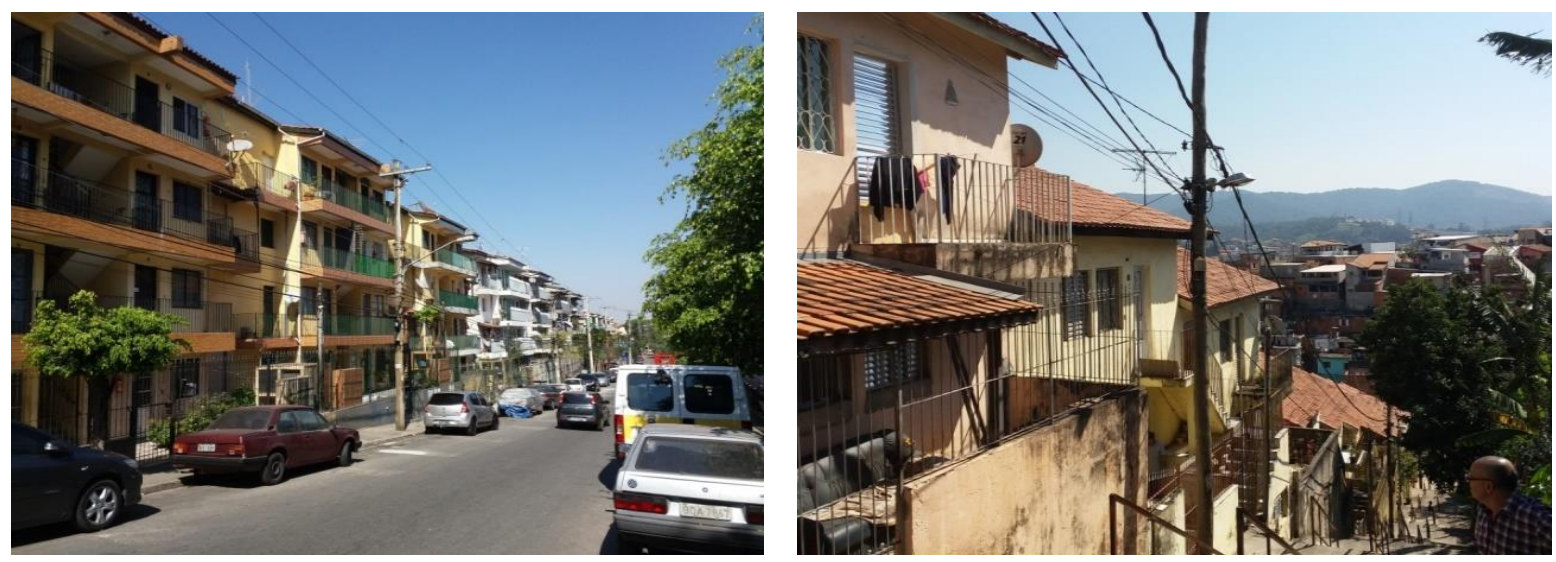

Fonte: Fotos, arquivo dos autores.

Figura7: Setor1 - Conjunto Jardim Apuanã, planta de uma prumada de apartamentos
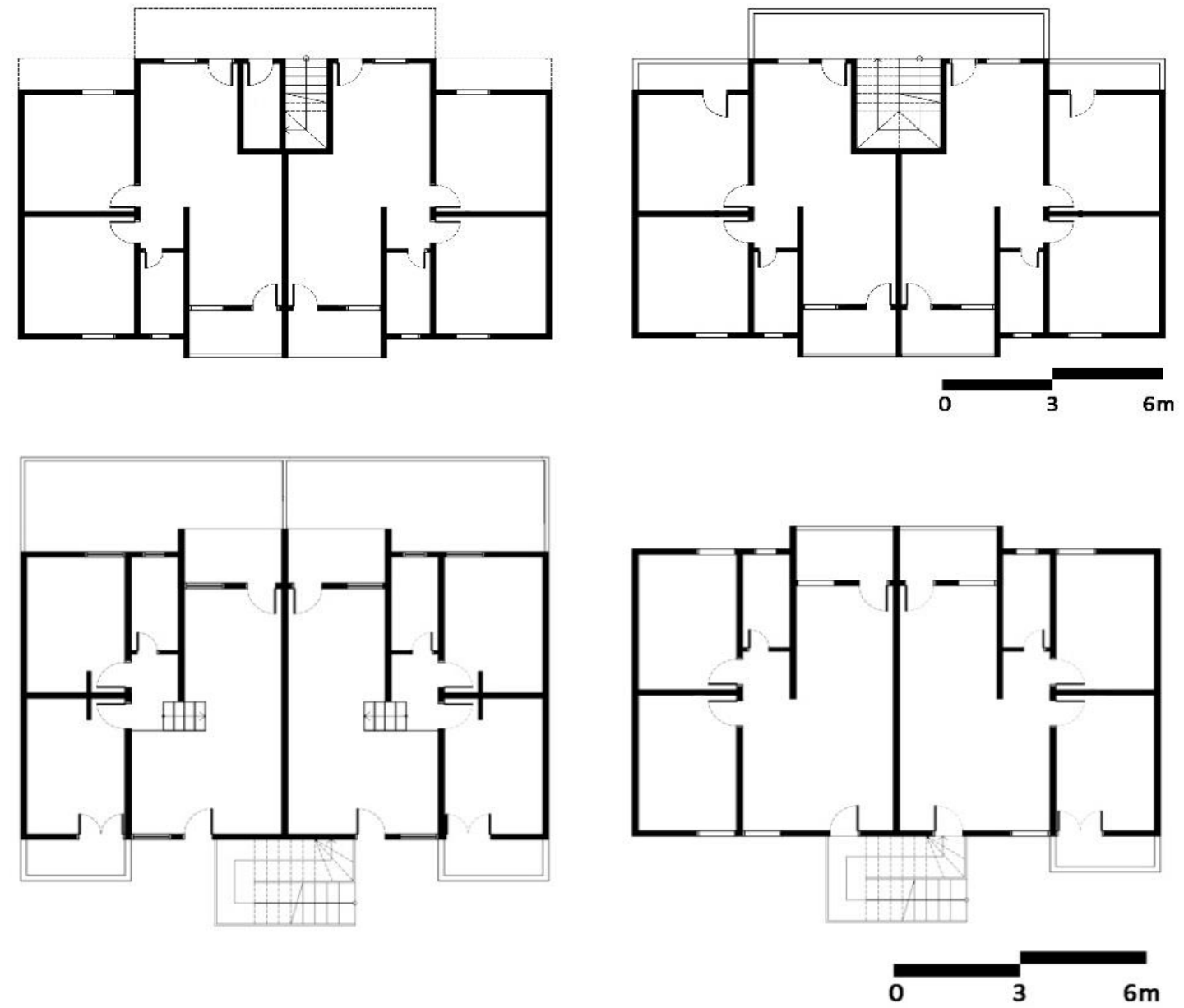

Fonte: Desenho dos autores. 
Macedo, A. C.; Damasceno, R. L.

\section{Subsetor 2}

O subsetor 2 abraça o subsetor 1, aproveita ao norte área de pequena declividade, a leste o loteamento ajusta-se a declividade na direção do córrego por extensos patamares e na parte leste da área os lotes aproveitam a declividade em relação a outro córrego existente. O parcelamento das quadras e feito por lotes de tipo pequeno e médio. São destinados a residências e a usos mistos (moradia, pequeno comércio e/ou serviço). As quadras não são regulares. A sua forma resulta da adaptação ao terreno culminando em lotes de profundidade variada, figura 8.

Figura 8: Subsetor 2

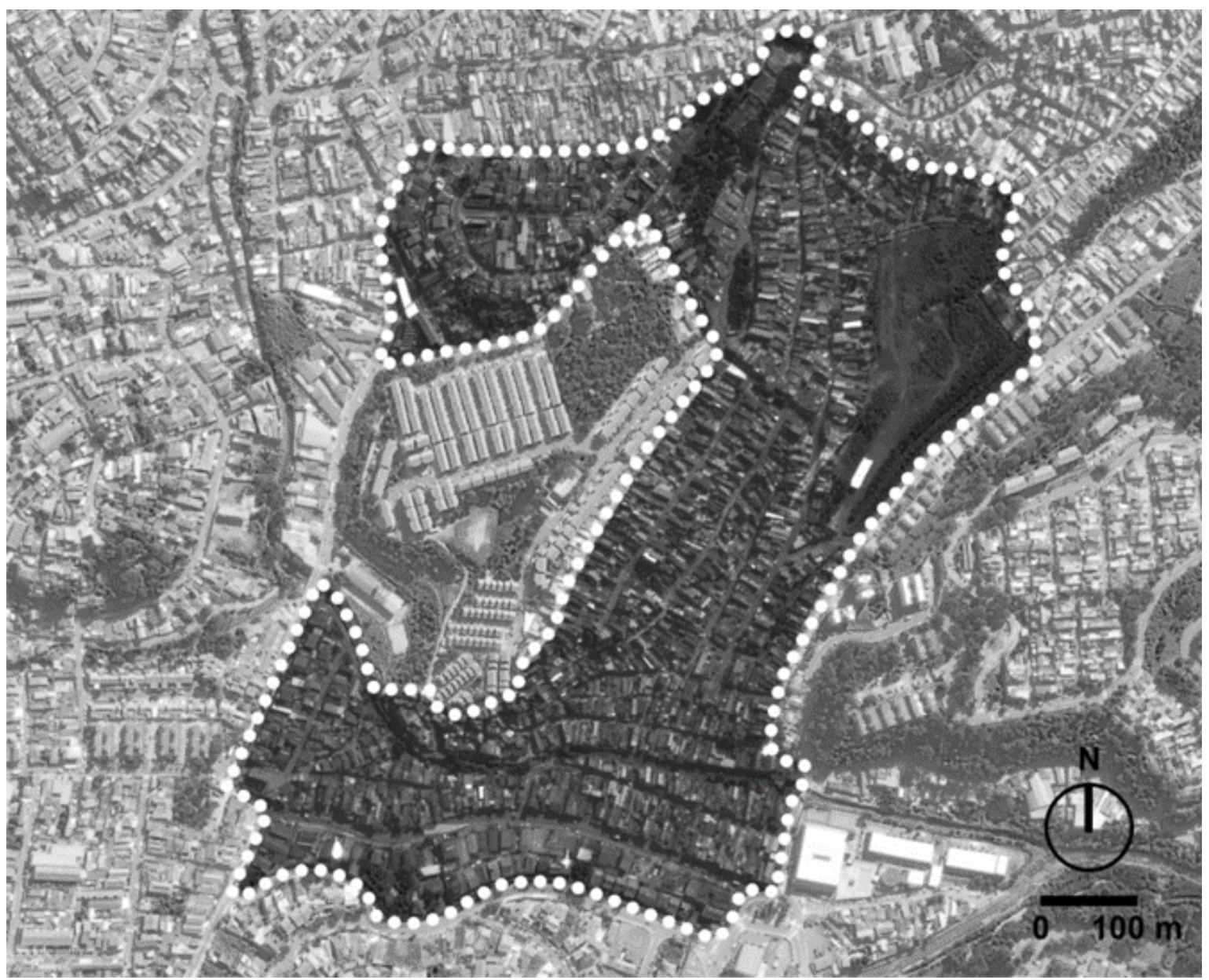

Fonte: Google Earth, diagrama dos autores.

No Subsetor 2, há uma incidência maior de ocupações irregulares em lotes que, geralmente, possuem área de $125 \mathrm{~m}^{2}$, de acordo com o que atualmente é estabelecido como lote mínimo. O que não impede que nestes lotes se construa para abrigar mais do que uma família. Nesse subsetor é recorrente a identificação de vazios no interior dos lotes, sendo que muitas vezes o recuo frontal não é adotado. A configuração de lotes pequenos e estreitos contribui para a ausência de áreas permeáveis dentro dos terrenos. Bem como, a largura estreita das vias dificulta a plantação de árvores no passeio. Alguns trechos de cobertura vegetal, neste subsetor, estão concentrados em lotes desocupados (Figura 9).

O assentamento das edificações nessa área, devido à declividade acentuada, ocasiona diferenças de gabarito entre os dois lados da via; o tamanho reduzido da caixa das ruas dificulta a entrada de luz natural e revela um tipo de ocupação que, se inicia com as edificações e depois vem o acabamento das vias. Diretrizes urbanísticas básicas, como respeitar o recuo das edificações ou a largura de calçada, não são respeitadas e isto reflete em uma maneira de construir que materializa a informalidade (Figura 10). 

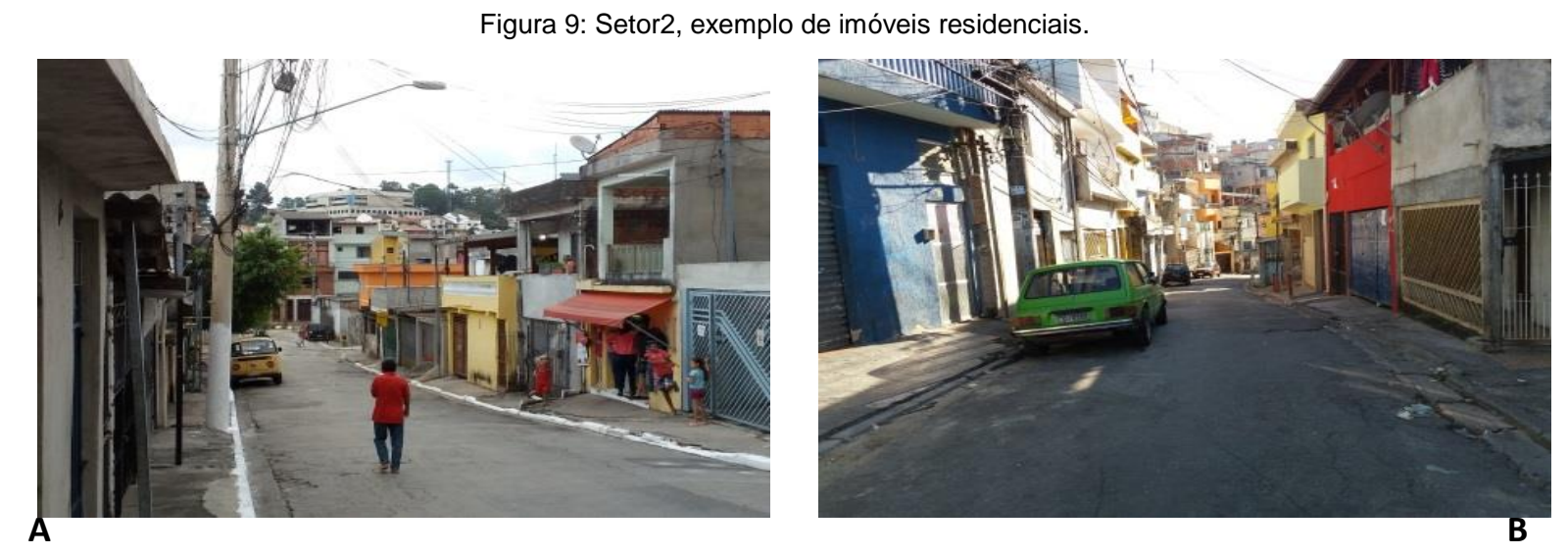

Fonte: Fotos, arquivo dos autores.

Figura10: Setor 2, plantas tipo.
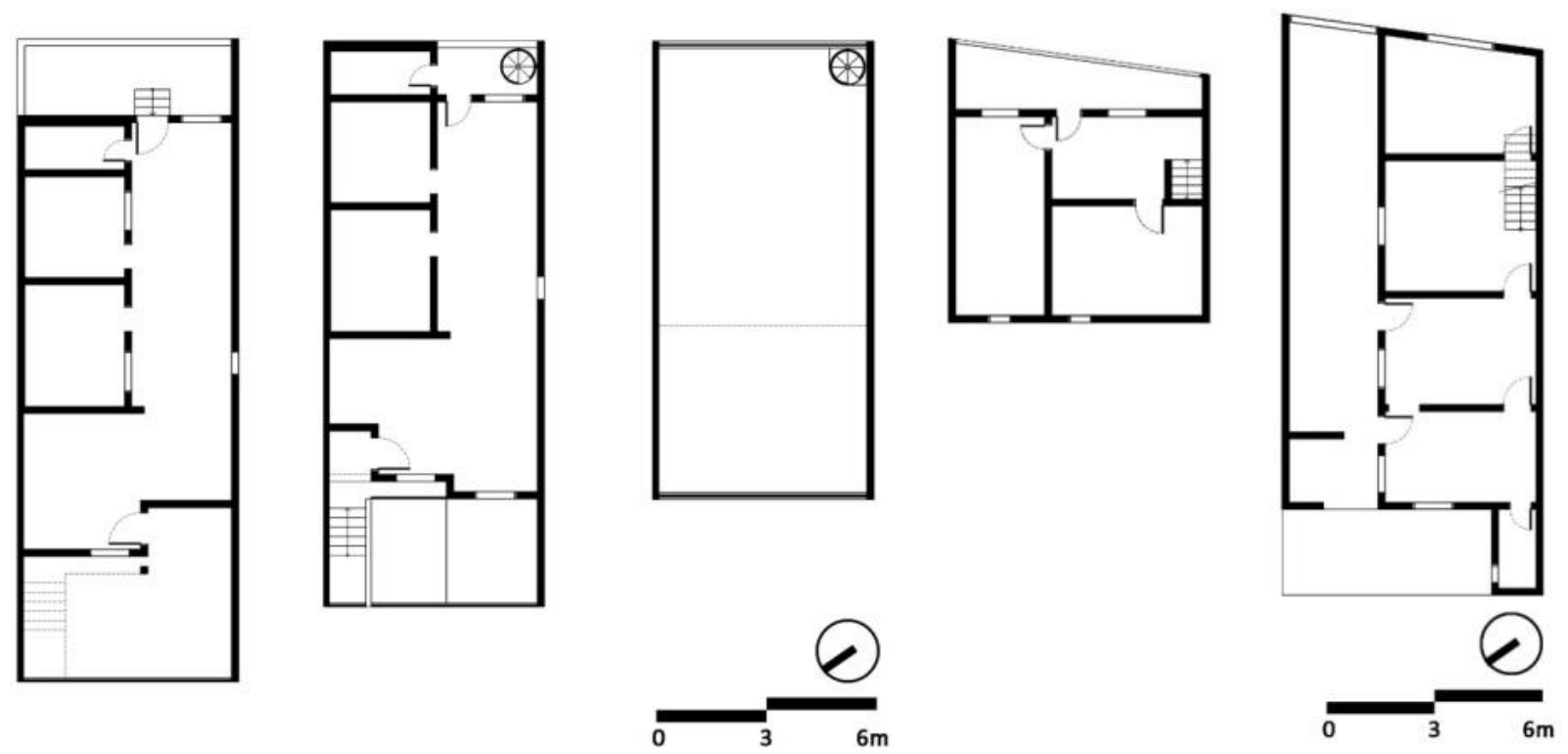

Fonte: Diagrama elaborado pelos autores.

\section{Subsetor 3}

O subsetor 3 se caracteriza por ter sido implantado ao redor da Associação Atlética Guapira, um clube privado localizado no topo da colina. Ao seu redor estão distribuídas casas de alto padrão implantadas em um loteamento que se ajusta bem às curvas de nível. O clube foi fundado em 1918 por moradores e comerciantes locais, visando a formação de uma equipe de futebol. O clube instalou-se em diferentes localidades do bairro do Tremembé até adquirir, em 1964, a parcela de 50 hectares em que está localizado atualmente.

O parcelamento dos terrenos no entorno do clube começa a ocorrer a partir da década de 1970, segundo dados da Prefeitura de São Paulo. Neste subsetor, no traçado das vias foram dimensionados passeios de três metros de largura, permitindo a plantação de árvores nas calçadas. Os leitos carroçáveis são suficientemente dimensionados, existem canteiros centrais em alguns pontos e dispositivos separadores de tráfego (Figura 11).

O parcelamento de lotes é feito por lotes com área variando de 250 a $400 \mathrm{~m}^{2}$. Além disso, as edificações respeitam os recuos obrigatórios de frente, laterais e fundos, condição que o identifica com um local de classe média. Este subsetor é o mais privilegiado quanto à presença de vegetação, devido à plantação de árvores no passeio de três metros de largura, a presença de mata ciliar no Córrego Tremembé, circundando o subsetor, bem como dentro dos domínios do Clube Guapira. 
Macedo, A. C.; Damasceno, R. L.

Outro fator que contribui para a existência de generosa quantidade de vegetação devido à plantação de árvores nos terrenos privados. Conclui-se que a distribuição do verde acontece de forma mais homogênea neste subsetor, reforçando o padrão de classe média (Figuras 11 e 12).

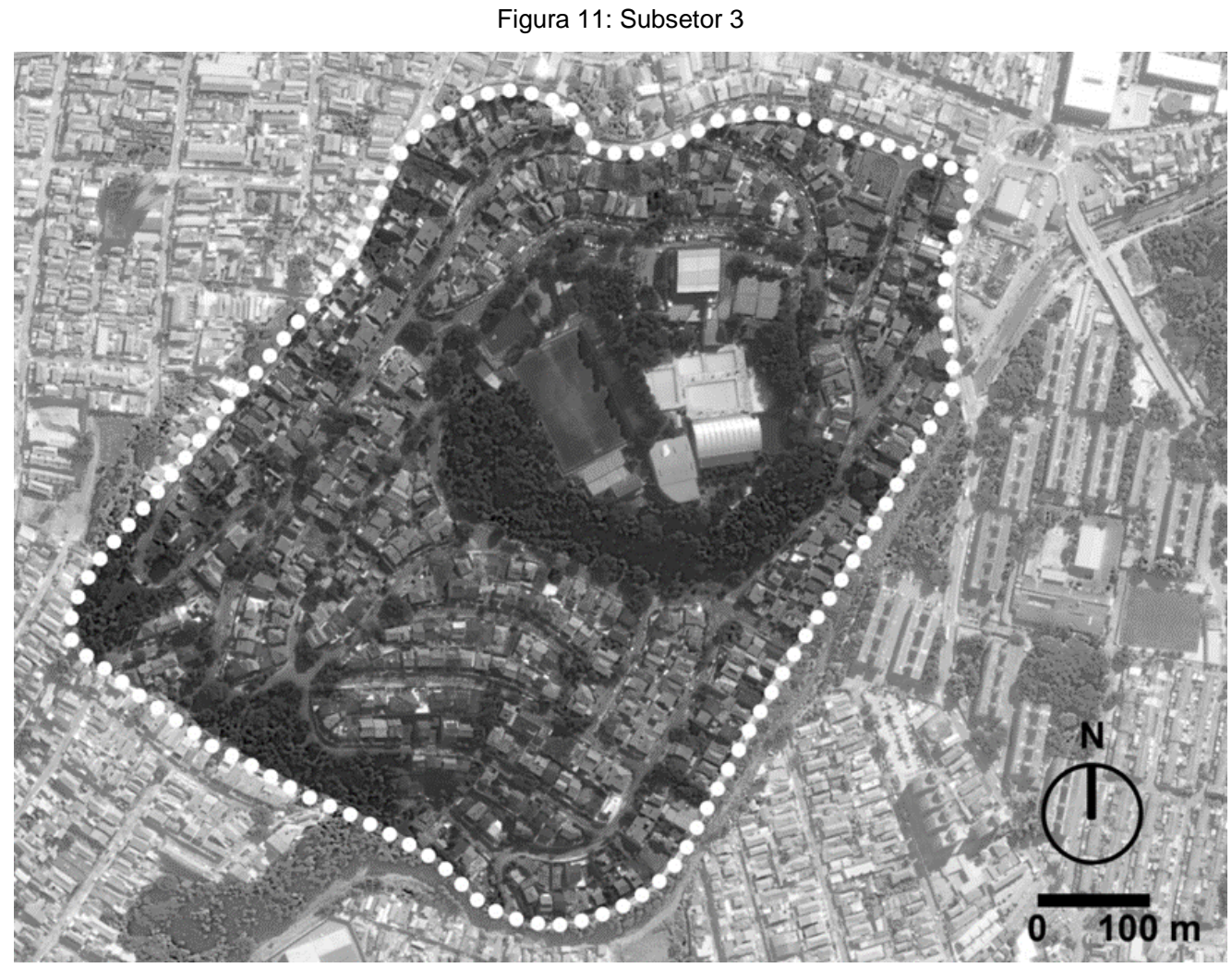

Fonte: Google Earth, diagrama dos autores.

Figura 12: Subsetor 3, exemplos de imóveis residenciais
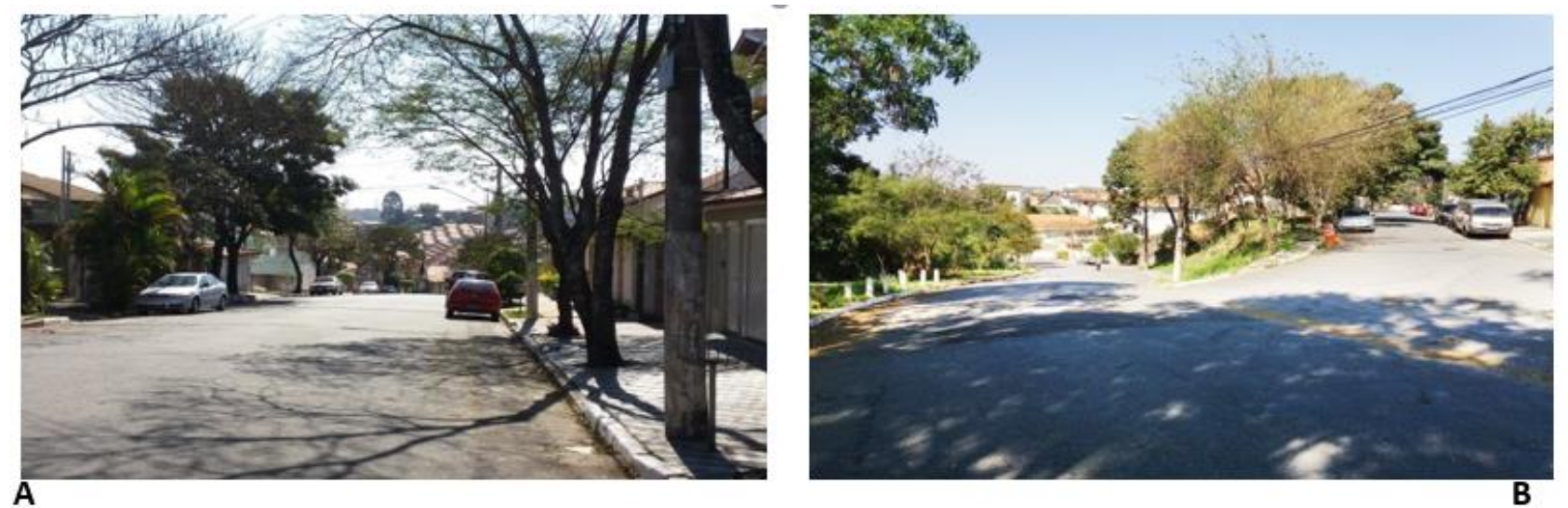

Fonte: Fotos arquivo dos autores.

\section{CONSIDERAÇÕES FINAIS}

O artigo mostra o estudo da forma de um setor do tecido da cidade de São Paulo, ressaltando o procedimento de aplicação dos conceitos de corredor e subárea. Tal procedimento permitiu se identificar os menores subsetores de um setor maior em análise, sendo utilizado no Tremembé para demonstrar-se a relação das formas construídas com situações socioeconômicas díspares, porém convivendo de muito próximo umas das outras, como assentamento urbano. A posição relativa à declividade do terreno e os tipos de construção 
encontradas, em particular das moradias, demonstram o lado simbólico de representação desta realidade quanto à disputa por um lugar para viver.

Procurou-se, no artigo, explicitar uma maneira de desenvolver investigações sobre a forma urbana, inicialmente ao reportar os aspectos conceituais da disciplina de projeto urbano e seus fundamentos teóricos, depois quanto ao projeto, cujo primeiro passo é justamente o conhecimento detalhado do local e o resgate dos propósitos que ensejaram a construção.

Quanto à pesquisa sobre o projeto ora implantado, embora tenha havido possibilidade de transitar livremente nos espaços públicos, verificou-se grande dificuldade para adentrar os imóveis, condição compreensível devido a insegurança que hoje paira no Brasil. Observadas as inúmeras variações sobre um tipo edificado ou padrão inicial, resultante do modo de viver (as vezes sobreviver) de uma parte das famílias, entende-se que foi reforçada a opção de não se ir a fundo nas questões individuais e trabalhar-se apenas com os tipos gerais, possíveis de serem percebidos e que se fazem marcantes como forma edificada. Disto resultou a observação de padrões de uso dos espaços e o estudo de tipos.

\section{REFERÊNCIAS}

ALEXANDER, C.; ISHIGAWA, S.; SILVERSTEIN, M. Uma linguagem de padrões. Porto Alegre: Bookman, 2013 (original de 1977).

BARNETT, J. Redesigning cities: principles, practice, implementation. Chicago: American Planning Association. 2003.

CHERRY, N.; NAGLE, K. Grid, Street, Place, essential elements of sustainable urban districts. Chicago: Planners Press, 2009.

COELHO, C. D. [coord.]; CALADO, M.; COSTA, J. P. [et al.]. Morfologia urbana da cidade portuguesa. Os elementos urbanos 1. (Coleção Cadernos MUrb). Lisboa: Argumentum, 2013.

EWING, R.; BARTHOLOMEW, K. Pedestrian \& transit-oriented design. New York: Urban Land Institute, 2013.

MACEDO, A. C.; O espaço urbano por partes. São Paulo. Revista Sinopses n³8, São Paulo: FAAUUSP, outubro 2002, pp. 11-16.

ROSSI, A. A arquitetura da cidade. São Paulo: Martins Fontes, 2001 (original de 1966)

SOLÁ-MORALES, M. Las formas de crescimiento urbano. Barcelona: Ediciones UPC, 1997

NOTA DO EDITOR (*) O conteúdo do artigo e as imagens nele publicadas são de responsabilidade do(s) autor(es). 